\title{
Practical implications for the implementation of the new international airport pavement strength rating system
}

\author{
G. White \\ School of Science and Engineering, University of the Sunshine Coast, Sippy Downs, Queensland, Australia
}

\begin{abstract}
Since 1981, most airports have used an internationally standardized method of airport pavement strength rating, which is based on simple pavement analysis models and categorical subgrades. With the broad implementation of mechanistic-empirical layered elastic pavement design methods, a mis-match between pavement thickness determination and pavement strength rating has evolved. To address this, a new system is being implemented that uses the same layered elastic model for strength rating as is used for pavement thickness determination in the United States and new subgrade categories, taken from French road design. Case studies on four Australian airports indicate how the new system may be implemented in countries that do not mandate prescriptive methods of pavement strength rating, rather using engineering judgment exercised by specialist engineers based on historical using aircraft, historical pavement performance and reverse engineering of existing pavement structures. The transition to the new system will create some challenges, mostly for those airports that do not know the basis of their current strength rating and can not locate historical existing pavement composition and subgrade bearing strength data. The cost of transition is estimated to be significant and is not justified because the new system provides no practical benefit to most airports in Australia.
\end{abstract}

Keywords: Runway, strength, ICAO, PCN, PCR

\section{INTRODUCTION}

Since their first introduction in the early 1900s, aircraft have become larger and heavier. Particularly since WWII, aircraft wheel loads and tyre pressures have increased significantly (Roginski 2007; Fabre et al. 2009) and this requires ever-stronger pavements to be provided by airports. In 1958, the USA Federal Aviation Administration (FAA) implemented a policy to restrict the development of new aircraft that stressed pavements more than a DC8-50 aircraft operating at $159 \mathrm{t}$. In 2009 the FAA pavement protection policy was withdrawn, effectively allowing more demanding aircraft to be developed without restriction (Rodway 2009). Consequently, the provision of airport pavements capable of accommodating any more demanding future aircraft became the responsibility of airport owners. The trend of increasing aircraft tyre pressures and individual wheel loads has continued since that time and is not expected to abate in the future.

To assist airport owners and operators to control and manage the impact of different aircraft on their pavements, the International Civil Aviation Organisation (ICAO) introduced an internationally recognised system for airport pavement strength rating in 1981 (CROW 2003). The system is known as the Aircraft Classification Number (ACN)-Pavement Classification Number (PCN) system and is subscribed to by the approximately 200 member States of ICAO

DOI: $10.1201 / 9781003222880-20$ 
(ICAO 2020). As detailed further below, every aircraft has a mathematically exact ACN, based on the weight of the aircraft, its tyre pressure and the bearing capacity of the subgrade over which it operates. The pavement subgrade bearing capacity is important because it determines the approximate depth of the covering pavement and therefore the degree of interaction between the 2, 4 or 6 wheels on any given aircraft landing gear leg or truck. The ACN of a particular aircraft is compared to the PCN assigned to a particular pavement. If the ACN is equal to or less than the PCN, the aircraft is permitted to operate without restriction. When the ACN is greater than the PCN, the airport operator must seek the airport owner's permission to operate, under what is known as a Pavement Concession.

Unlike the ACN of an aircraft, the PCN of a pavement is not mathematically exact and is subject to the discretion of the airport owner. Some ICAO member States prescribe the method of PCN determination for the airports under their jurisdiction. For example, the FAA of the USA has a formal process for PCN determination (FAA $2014 \mathrm{~b}$ ). This reflects the centralised role of the FAA in providing significant funding towards airport pavement construction and upkeep, via the Airport Improvement Program (FAA 2020). In contrast, Australia provides only minimal guidance regarding methods for PCN determination (CASA 2011). This reflects the Australian Government's divestment from civilian airport ownership in the 1990s and allows private airport owners to set the PCN of the runway at any value they wish, based on the aircraft they wish to attract in order to increase the associated level of income. Importantly, in Australia, a private airport owner also pays for airport pavement construction and maintenance, meaning the private airport owner must consider the increased pavement damage associated with a higher PCN value, against the increase in revenue that it allows.

In the USA and some other States, where a prescriptive and formal process of PCN determination is followed, challenges have occurred due to a difference in the mathematical models used for pavement thickness design and those used for PCN determination. As explained below, modern airport pavement thickness design is based on layered elastic and/or finite element calculation of strain as the indicator of damage within a realistic pavement structure (Wardle \& Rodway 2010). In contrast, the software prescribed for aircraft ACN calculation, and therefore PCN assignment, uses Boussinesq-based deflection as the damage indicator within a standard pavement composition (FAA 2014a). Non-standard compositions, which are common, must be converted to an equivalent standard thickness, using material equivalent factors (FAA 2014a). This difference can lead to a pavement being designed for a specific aircraft and then having a PCN assigned that requires that same aircraft to operate under a Pavement Concession. That is, the pavement is assigned a PCN that is lower than the ACN of the aircraft that it was designed for, which is illogical.

To avoid this challenge in the future, ICAO has developed a replacement for the ACNPCN system. The ACN is replaced by an Aircraft Classification Rating (ACR) and the PCN is replaced by a Pavement Classification Rating (PCR). The ACR-PCR system is intended to operate on the same principles as the ACN-PCN system with one primary difference. ACR values are calculated using the critical strain in the same layered elastic model that is used in the FAA's pavement thickness design software FAARFIELD (FAA 2017). However, to replace the ACN-PCN system with the ACR-PCR system requires all aircraft manufacturers to determine and publish ACR values. It also requires every airport in every ICAO member State to change their PCN to an equivalent PCR.

This paper presents examples of the transition from ACN-PCN to ACR-PCR for different airports that are typical of the 400 significant and paved airports in Australia (AAA 2017). First the two pavement strength rating systems are compared and trends in the relationship between ACN and ACR values are explored. Four examples are then presented as case studies of the transition. Finally, transitional and implementation issues and challenges are compared to the benefit that the new pavement strength system will provide. Although this paper is presented in the context of flexible Australian airport pavements, the findings also apply to other ICAO member States that generally allow airports to determine the basis of their pavement strength rating. 


\section{BACKGROUND}

\subsection{Australian Airport pavements}

Like road and highway pavements, airport pavements are designed to protect the natural or imported subgrade from the traffic loads they are expected to support over their design life. Furthermore, airport pavements are generally either rigid or flexible in nature, although some composite pavements are also used (Deilami \& White 2020). Traditionally, flexible airport pavements were designed to comprise thick layers of well compacted and high quality fine crushed rock (FCR) base over uncrushed gravel sub-base with a thin bituminous surfacing. The pavement thickness was determined using the methods developed by the US Army Corps of Engineers (Corps) between the 1940s and 1970s (Ahlvin 1991). Since that time, many counties have developed significantly different pavement styles, with much thicker asphalt, bound or stabilised sub-base layers and some use full depth asphalt structures (White et al. 2020). However, Australia largely retains the Corps approach to airport pavement design and all Australian runways are comprised of a flexible pavement structure (AAA 2017). One aspect of airport pavement practice that is generally peculiar to Australia is the significant use of a sprayed bituminous surface directly over granular base course (White 2019). This reflects the large number of Australian airports that are associated with smaller commercial aircraft in remote areas and the high cost of providing asphalt surfaces in these remote locations (AAA 2017). Importantly, all Australian airports subscribe to the ACN-PCN system of pavement strength rating and all rated airports publish their PCN in the public domain.

\subsection{ACN-PCN system}

As stated above, the ICAO airport pavement strength rating system is known as ACN-PCN. Aircraft loads are expressed by an ACN which allows no discretion. For a specific aircraft at a given operating mass and tyre pressure, there is only one ACN per pavement subgrade category. The ACN is defined as twice the wheel load (in tonnes) which on a single wheel, inflated to $1.25 \mathrm{MPa}$, causes vertical pavement deflection (calculated at the top of the subgrade) equal to that caused by the actual multi-wheel aircraft gear, at its actual gear load and its actual tyre pressure. The interaction between multiple wheels of a specific landing gear changes with pavement depth. This means that two aircraft with different landing gear configurations, but the same ACN for a particular subgrade category, will cause relatively different damage to pavements with different thickness. Pavement thickness is also significantly affected by subgrade stiffness, usually expressed as the California Bearing Ratio (CBR). The application of ACN-PCN therefore changes with subgrade CBR. Rather than a continually varying ACN across all possible subgrade CBR values, subgrades are categorised and a representative CBR adopted (ICAO 2013):

- Category A. High strength. Represented as CBR 15.

- Category B. Medium strength. Represented by CBR 10.

- Category C. Low strength. Represented by CBR 6.

- Category D. Ultra-low strength. Represented by CBR 3.

The PCN is presented as a multi-element expression, such as the example in Equation 1. The main element is the number against which the ACN is compared. It is intended to protect the pavement structure from overloading, primarily based on permanent subgrade deformation, also known as pavement rutting. The tyre pressure limit is secondary and is compared to the operating tyre pressure of the aircraft and is intended to protect the surface from high near-surface stress.

$$
P C N 58 / F / A / X / T
$$

Where: 58 is the numerical element against which the ACN is compared. $\mathrm{F}$ is to indicate a Flexible pavement, rather than $\mathrm{R}$ for Rigid. 
$\mathrm{B}$ is the category of subgrade detailed above.

$\mathrm{X}$ is the tyre pressure limit category detailed above.

$\mathrm{T}$ is to indicate a Technical assessment rather than $\mathrm{U}$ for a Usage based assessment.

The tyre pressure limits are categorical in nature and are inherently empirical. Aircraft with tyre pressures less than the assigned category limit are permitted to operate without specific approval from the airport owner. Aircraft with higher tyre pressures require a Pavement Concession. Some countries, such as Australia, have adopted airport-specific tyre pressure limits rather than tyre pressures categories and category limits (ASA 2020).

In 2008 increases in the tyre pressure limits were proposed by aircraft manufacturers (Rodway 2009). After some full-scale testing, the proposed increase in the categorical tyre pressure limits of the ACN-PCN system was approved by ICAO in 2013 (Roginski 2013). Table 1 provides the original and revised tyre pressure limits. This change allowed an increase in aircraft tyre pressure from 1.50 MPa to $1.75 \mathrm{MPa}$ to operate on airports with a Category $\mathrm{X}$ tyre pressure limit.

Table 1. ACN-PCN Tyre Pressure Category Limits.

\begin{tabular}{lll}
\hline Category & Original Tyre Pressure Limits & Revised Tyre Pressure Limits \\
\hline $\mathrm{W}$ & Unlimited & Unlimited \\
$\mathrm{X}$ & $1.50 \mathrm{MPa}$ & $1.75 \mathrm{MPa}$ \\
$\mathrm{Y}$ & $1.10 \mathrm{MPa}$ & $1.25 \mathrm{MPa}$ \\
$\mathrm{Z}$ & $0.50 \mathrm{MPa}$ & $0.50 \mathrm{MPa}$ \\
\hline
\end{tabular}

As stated above, some jurisdictions publish standard procedures for the formal calculation of the PCN. In the USA, FAA (2014) requires an airport to determine a runway PCN by generally:

- Converting the actual pavement structure to an equivalent thickness of a standard structure. This is often complicated because actual pavement structures in the USA are generally different to the standard pavement composition in COMFAA, which is $75 \mathrm{~mm}$ of P-401 (asphalt) on $150 \mathrm{~mm}$ of P-209 (crushed rock) on the required thickness of P-154 (uncrushed gravel).

- Determining the critical aircraft, which is the aircraft that is predicted to consume the largest portion of the pavement's design life, based on the actual number of passes included in the traffic mix for pavement thickness design. This is often the aircraft with the highest $\mathrm{ACN}$, but can be an aircraft with a lower $\mathrm{ACN}$ when the traffic mix includes a large number of the less damaging aircraft, compared to the aircraft with the higher ACN value.

- Determining the weight of the critical aircraft that would result in it causing the same total pavement damage in the predicted number of passes that all the aircraft caused when they were converted to an equivalent number of passes of the critical aircraft.

- Determine the ACN of the critical aircraft, at its increased/decreased weight, that produces the same damage as all of the aircraft in the aircraft traffic spectrum at the weights and load repetitions that were used in pavement design.

- Assigning that ACN value as the PCN of the pavement, which can be higher than all the actual ACN values of all the aircraft that the pavement was designed for.

When an aircraft with a relatively high $\mathrm{ACN}$ is predicted to operate at relatively low frequency, this process can result in an PCN that is unreasonably high and the FAA requires that a minimum 1,000 coverages be adopted over a 20 year design life (FAA 2014b). Although this formal method reduces the ability for an airport to arbitrarily over-rate or under-rate the strength of a runway pavement, it still requires some discretion when an irregular aircraft has 
the highest ACN. Furthermore, in some instances, an aircraft that is less damaging during design can be found to be more damaging during PCN determination. This reflects the difference in relative damage when the damage is determined using maximum deflection in a Boussinesq model of equivalent standard thickness, compared to using strain in a layered elastic based realistic pavement model. For example, 1,000 annual departures of the aircraft in Table 2 all require the same $428.6 \mathrm{~mm}$ thickness of flexible deep asphalt pavement on CBR 6 subgrade. However, the associated flexible ACN values for subgrade $\mathrm{C}$ are only approximately equal, meaning that a pavement designed for the B767-300 and assigned a PCN of 50, would not allow all the other aircraft to operate without a Pavement Concession, even though all require the exact same pavement thickness and are therefore considered to be equally damaging. Although the practical significance of a ACN value of 52, compared to a value of 50, is likely to be low, the rigid system adopted in the USA, and the inexperienced and sometime conservative nature of airport owners and managers, often results in Pavement Concessions and PCN assignment being viewed in a black and white manner. This makes small mismatches between airport pavement thickness design and airport pavement strength rating/management, a much more significant issue in practice than it should be.

Table 2. Example ACN (C) values for equal FAARFIELD pavement thickness.

\begin{tabular}{lll}
\hline Aircraft & Mass & ACN $(C)$ \\
\hline B737-800 & $79.2 \mathrm{t}$ & 50.3 \\
A321-200 & $82.0 \mathrm{t}$ & 51.6 \\
B767-300 & $156.1 \mathrm{t}$ & 49.5 \\
A350-900 & 193.9 & 50.8 \\
B777-300ER & 242.3 & 49.7 \\
A350-1000 & 236.5 & 51.8 \\
\hline
\end{tabular}

Note: Aircraft masses adjusted to require the same thickness as the B737-800 at standard mass. Pavement modelled as the required thickness of P401 (asphalt) over $150 \mathrm{~mm}$ of P154 (sub-base) over a CBR 6 subgrade.

\section{ACR-PCR SYSTEM}

To overcome the discrepancy between layered elastic based pavement thickness determination and Boussinesq based PCN calculation, ICAO has developed a replacement system (Fabre 2018). As stated above, the new ACR-PCR system was designed to be more rationale by using a critical strain calculated by layered elastic methods as the indicator of damage. The new system was developed by ICAO's Airport Pavement Expert Group over the period 2014-2018 and approved by ICAO in 2019 (Fabre 2019). The new system became applicable in July 2020 and will be effective in November 2024. That means that between July 2020 and November 2024, all ICAO member States will need to transition from ACN-PCN to ACR-PCR. Similarly, all aircraft manufacturers will need to publish ACR information for their aircraft and must publish both ACR and ACN data during the transition period, during which time some ICAO member States will be using ACRPCR, but others will still be using ACN-PCN.

The ACR-PCR system was developed to be based on the same principles and mechanics as the ACN-PCN system. Despite the apparent similarities in the two systems, ACR-PCR system includes significant changes (Fabre 2019):

- Strain used as the relative damage indicator, rather than deflection.

- All wheels considered explicitly, rather than being converted to an equivalent single wheel.

- Actual pavement materials and composition considered explicitly, rather than being converted to a standard composition that is rarely used in many countries. 
- Load repetitions, tyre pressures and pavement structures selected to be more comparable to typical modern airport pavement structures.

- Rigid and flexible pavement subgrade categories use the same elastic modulus (or CBR) ranges and removal of the largely discontinued $\mathrm{k}$-value (modulus of subgrade reaction) for rigid pavement subgrades.

The term ACR-PCR was adopted to avoid confusion with ACN or PCN values. Furthermore, the ACR is defined as twice the equivalent wheel load in hundreds of kilograms, rather than in tonnes. This means that ACR values generally range from 50 to 1000 , compared to $\mathrm{ACN}$ values which generally range from 5 to 100 . This change was also designed to avoid confusion between the two systems.

\subsection{Comparing the two systems}

As stated above, the ACR-PCR system was developed to be based on layered elastic methods and to be more representative of modern typical pavement structures and aircraft. However, ACR-PCR was developed to operate in a similar manner to ACN-PCN. That is the aircraft ACR is compared to the pavement PCR. If the PCR exceeds the ACR, then the aircraft can operate without restriction. However, when the ACR exceeds the PCR, a Pavement Concession is required. Also similar to the ACN-PCN system, the tyre pressure limit check is also required, and this is effectively unchanged by the transition to ACR-PCR.

The main differences between ACN-PCN and ACR-PCR relate to the basis on which the equivalent wheel load is determined, and include (Fabre 2019):

- Standard tyre pressure.

- Standard pavement structures.

- Subgrade categories.

- Calculated indicator of relative damage.

The standard wheel load, to which other landing gear loads are converted, now has a 1.50 $\mathrm{MPa}$ tyre pressure to better reflect large modern aircraft, compared to the $1.25 \mathrm{MPa}$ tyre pressure used to calculate $\mathrm{ACN}$ values. The flexible standard pavement structure has greater asphalt thickness and now depends on the number of wheels in the landing gear being considered. Table 3 shows the two flexible pavement structures. The rigid pavement structure is not affected by the number of wheels in the landing gear, as shown in Table 4.

Table 3. ACR-PCR standard flexible pavement structures.

\begin{tabular}{llll}
\hline Layer & ACN-PCN thickness & $\begin{array}{l}\text { ACR-PCR thickness } \\
\text { for 1-2 wheels }\end{array}$ & $\begin{array}{l}\text { ACR-PCR thickness } \\
\text { for 3 or more wheels }\end{array}$ \\
\hline $\begin{array}{l}\text { Asphalt surface (P401/403) } \\
\text { Crushed rock (P209) }\end{array}$ & $75 \mathrm{~mm}$ & $76 \mathrm{~mm}$ & $127 \mathrm{~mm}$ \\
Uncrushed gravel (P154) & As required & As required & As required \\
Subgrade & Infinite & Not used & Infinite \\
\hline
\end{tabular}

Table 4. ACR-PCR standard rigid pavement structures.

\begin{tabular}{lll}
\hline Layer & ACN-PCN thickness & ACR-PCR thickness \\
\hline Concrete base (P501) & As required & As required \\
Crushed rock (P209) & Combined with subgrade & $200 \mathrm{~mm}$ \\
Subgrade & Infinite & Infinite \\
\hline
\end{tabular}


The standard subgrade categories have been adjusted to be the same for rigid and flexible pavements and now correspond to subgrades categories used in France for road and highway pavement design. Although the alignment of rigid and flexible pavement subgrade rating is supported, the selection of French roads and highways as the basis is arbitrary and will result in many aerodromes needing to change from one subgrade category to another, which will complicate the transition from ACN-PCN to ACR-PCR. The current and new subgrade categories are summarised in Table 5. Figure 1 then compares the subgrade CBR categories and highlights the representative values used for each category in the respective systems. Figure 1 also highlights the CBR values that will necessitate airports changing from one subgrade category to another.

Table 5. ACN-PCN and ACR-PCR flexible subgrade categories.

\begin{tabular}{lllll}
\hline & ACN-PCN system & \multicolumn{3}{c}{ ACR-PCR system } \\
\cline { 2 - 5 } Subgrade Category & Nominal CBR & CBR Range & Nominal CBR & CBR Range \\
\hline A & 15 & 13 and above & 20 & 15 and above \\
B & 10 & $8-12$ & 12 & $10-14$ \\
C & 6 & $4-8$ & 8 & $6-9$ \\
D & 3 & 4 and below & 5 & 5 and below \\
\hline
\end{tabular}

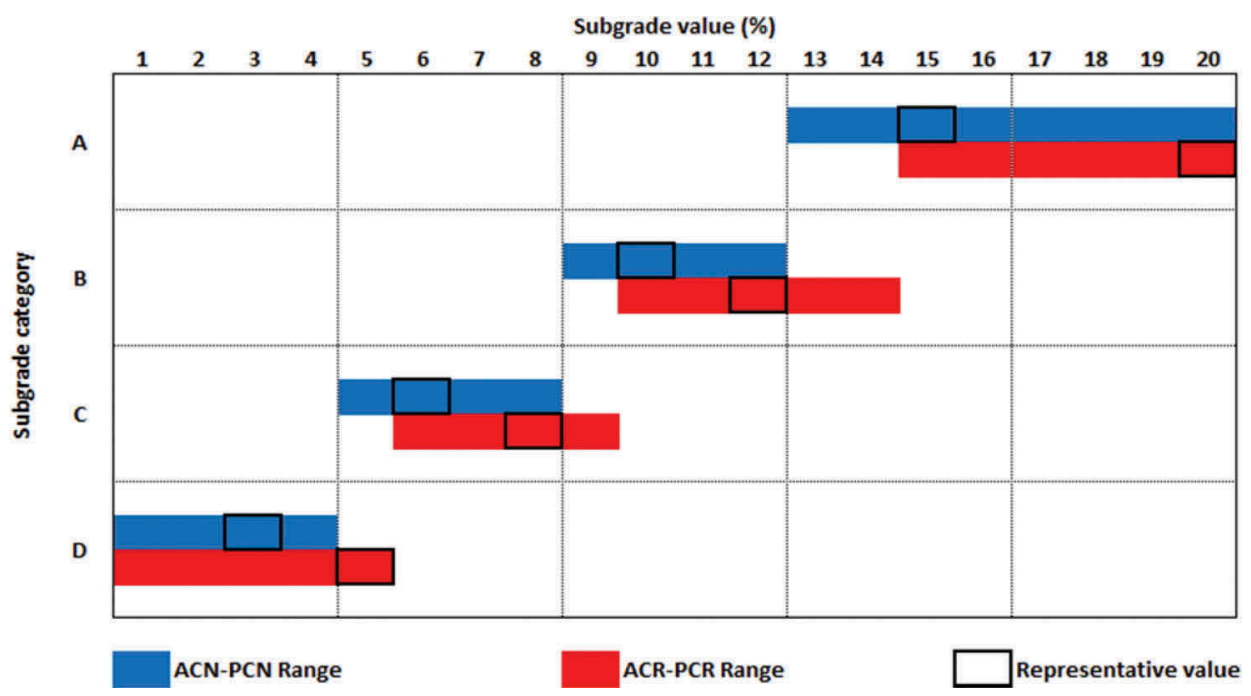

Figure 1. Flexible subgrade category ranges for ACN-PCN and for ACR-PCR.

The ACR-PCR system actually uses the elastic modulus of the subgrade (expressed in $\mathrm{MPa}$ ) to reflect the input into modern pavement thickness design software, but Table 5 shows equivalent CBR values using a simply linear conversion of 10 times. The use of elastic modulus avoids the need to estimate k-values for rigid pavements, which simplifies the ACR-PCR system for rigid pavements. The category D increase from CBR 3 to CBR 5 reduces the representativeness of the system for many Australian aerodromes that have old and poor natural subgrades with very low CBR values (White et al. 2021). 
The ACR-PCR indicator of relative damage caused by different aircraft is vertical strain at the top of the subgrade, instead of maximum deflection at the top of the subgrade. Furthermore, the layered elastic models in FAARFIELD (FAA 2020) are used to calculate the magnitudes of strain, rather than the simpler (Boussinesq) models used in COMFAA. This change reflects the more sophisticated computer power that is now readily accessible and greatly reduces the anomalies between pavement thickness design and strength rating in the USA. However, it means that the relationship between ACN and ACR is not fixed.

\subsection{Comparing $A C N$ and $A C R$ values}

Figure 2 Shows the ACR and ACN values for 17 common commercial and General Aviation (GA) aircraft on each of the four subgrade categories, ranging from the Super King Air 350 (6.9 tonnes) to the A380 (575 tonnes). On average, the ACR values were 9.5 times the ACN values for the same aircraft, with the ratios between ACN and ACR ranging from 7.7 to 12.0. It is these minor deviations away from ACR being 10 times

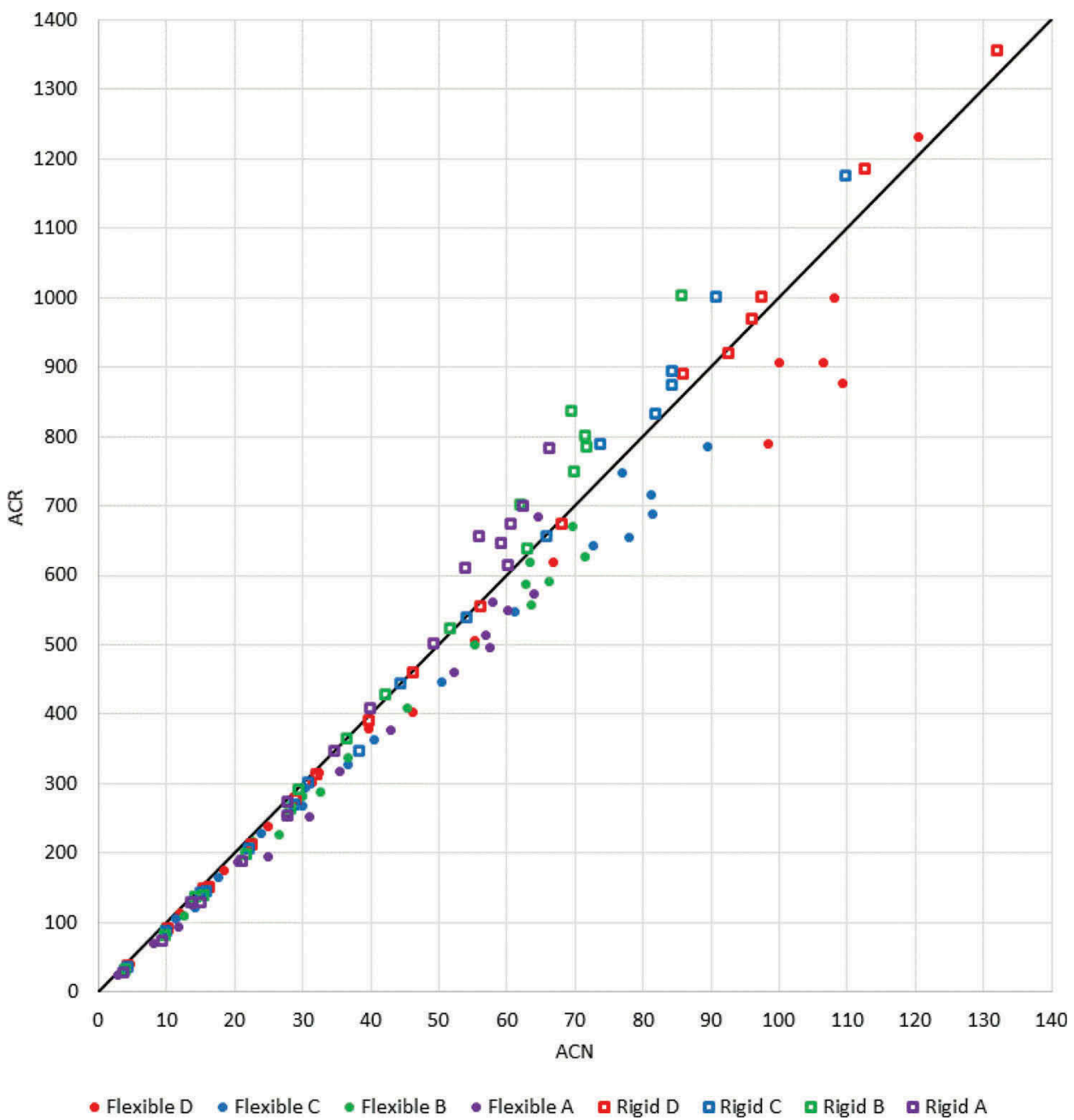

Figure 2. Comparison of ACN to ACR for various aircraft on rigid and flexible pavements. 
the ACN that will reduce the discrepancies between FAARFIELD designed aerodromes pavement thickness and COMFAA based pavement strength rating and PCN assignment.

It is important to understand that the conversion is not fixed and therefore some aircraft have an ACR value that is less than 10 times the ACN, while other aircraft will have an ACR value that is more than 10 times the ACN. This effectively means that the transition from ACN-PCN to ACR-PCR implies a difference in the relative damage caused by common aircraft. This has the potential to change the aircraft that is deemed to be the critical aircraft at any particular airport. Furthermore, Figure 2 generally indicates that:

- ACR-PCR predicts that on average, the same aircraft will do more damage to a rigid pavement than to a flexible pavement with the same PCN. That effectively requires rigid pavements to be thicker, relative to flexible pavements, than currently predicted by the ACN-PCN system.

- ACR-PCR predicts that smaller aircraft (one and two wheels) will be even less damaging, compared to larger (four and six wheels) aircraft, implied by ACN-PCN. The practical effect of this will vary depending on the mix of aircraft that operate at any particular airport. However, large aircraft always govern the strength rating of any airport pavement, so this will only affect airports with a strong main runway and a weak secondary runway, because one runway will likely have an PCR that is more than 10 times the PCN, while the other runway will likely have a PCR that is less than 10 times the PCN.

- The subgrade bearing strength (CBR indicated by the category) had no impact on the relationship between the $\mathrm{ACN}$ value and the ACR value.

\section{CASE STUDIES ON TRANSITION}

Other researchers and practitioners have presented examples of the application of ACRPCR (Fabre \& Vaurs 2017; Fabre 2018; Fabre 2019). However, these examples have generally been for large airports with complex aircraft traffic spectra. Most examples have also continued to be based on the prescriptive method of strength rating following in the USA (FAA 2014b; FAA 2020) and have focussed on the mechanics of that process. To balance these previous examples, this research presents the practical PCR determination for four different airports in Australia, where the prescriptive process for strength rating is not mandated. The airports were selected to demonstrate the range of complexities that are expected to arise as the system is imposed on all Australian airports. Note that Australia uses tyre pressure limits, rather than the categories shown in Table 1. However, the PCN and PCR expressions in the following examples are based on the applicable tyre pressure categories for simplicity and because the transition from ACN-PCN to ACR-PCN has no practical impact on the tyre pressure.

\subsection{Example 1-Mudgee airport}

The PCN for Mudgee airport is shown in Equation 2. The ' $U$ ' is important because it indicates that the strength rating is based on aircraft usage and not on a technical evaluation. This means that the basis of the strength rating is less likely to be clearly documented.

$$
\text { Mudgee current PCN } 12 / F / C / Y / U
$$

Review of their historical records indicated that Mudgee airport had been subject to two previous pavement investigations. Analysis of the records generally indicated that:

- The characteristic subgrade bearing strength was CBR 6\%. 
- Current regular aircraft are the JetSteam 41, which has an ACN on subgrade category C of 4.9 .

- Historical aircraft use included JetStream 32 (ACN 6.5), Saab 340B (ACN 8.2) and Fokker F27 (ACN 11.6).

The current regular aircraft operate with an ACN well below the PCN. It was therefore surmised that the current usage-based PCN value was based on the historical use of the F27, which is no longer in service. To determine an appropriate PCR, three options were considered:

- Set the PCR to the ACR of the JetStream 41.

- Set the PCR to the ACR of the Fokker F27.

- Perform a technical assessment of an appropriate PCN and convert that PCN to a PCN value, based on the adopted critical aircraft.

Using the ACR of the JetStream 41 was not recommended because it would likely underrate the pavement based on its historical rating and usage. Simply setting the PCR to the ACR of the F27 was considered to be unreasonable because the F27 no longer operates into Mudgee airport and is no longer a common aircraft in Australia. Therefore, the PCN was first determined using the information in the historical records, supplemented by a visual condition assessment. The assessment found that the Falcon 7X aircraft was suitable at an operating mass of 16.3 tonnes, which results in an ACN of 10. The equivalent ACR value is 92, resulting in the strength rating in Equation 3 (PCN) or equivalent rating in Equation 4 (PCR). Because subgrade CBR 6 is a category $\mathrm{C}$ subgrade under both strength rating systems, there was no requirement to change subgrade categories.

$$
\begin{aligned}
& \text { Mudgee recommended } P C N 10 / F / C / Y / T \\
& \text { Mudgee recommended } P C R 92 / F / C / X / T
\end{aligned}
$$

Mudgee airport was fortunate that historical records provided enough information to allow the PCN to be reviewed on a technical basis and the equivalent PCR value to be determined. However, the assessment took two days to be performed by a specialist engineer that was required to travel from inter-State to conduct the condition assessment, costing around AUD 5,000 .

\subsection{Example 2 - Birdsville airport}

The current PCN for Birdsville airport is in Equation 5. Again, the basis was not known to the airport staff and the ' $U$ ' indicates that it was historically based on using aircraft. The only significant and regular aircraft is the Saab $340 \mathrm{~B}$, which has an ACN (on subgrade B) of 6.5, which is significantly below the current PCN.

$$
\text { Birdsville PCN } 10 / \mathrm{F} / \mathrm{B} / \mathrm{Y} / \mathrm{U}
$$

Birdsville airport did not know its characteristic subgrade strength or the basis of its current strength rating and did not have a good understanding of its historical aircraft traffic that might be associated with the current PCN value. To understand these issues and to enable a transition to PCR, investigations were required, including:

- Condition assessment by a specialist engineer.

- Geotechnical testing.

- Analytical evaluation of the current pavement strength.

It was determined that the characteristic subgrade CBR value was 9. Although that is a category B subgrade under the ACN-PCN system, it is a category $\mathrm{C}$ under the ACR-PCR system, as shown in Table 5. The pavement was found to be adequate for projected operations 
of a CL 604 at 18.2 tonnes. The ACN of the CL 604 is 9.8 (on subgrade B) indicating that the current usage based PCN (Equation 5) is appropriate.

When converting this PCN to an equivalent PCR, the different subgrade category also needed to be accounted for. At 18.2 tonnes, the CL 604 has an ACR of 88 (subgrade B) and 98 (subgrade C). Because of the change in the subgrade category changes, the recommended PCR was based on subgrade category $C$, as shown in Equation 6.

$$
\text { Birdsville PCR 98/F/C/Y/T }
$$

In retrospect, Birdsville airport could have simply picked any aircraft with an ACN of 10 , on subgrade $\mathrm{C}$, and determined the ACR of that aircraft. However, that would rely on retaining the category $\mathrm{C}$ subgrade because the characteristic subgrade CBR was not known. Such an approach would have resulted in a PCN value of anywhere between 90 and 110, depending on the aircraft selected. However, this range of potential PCR values would not be of practical significance because the ACR of the Saab 340 B is just 43 (for subgrade category B).

The investigation of the existing pavement structures, and the determination of an accurate PCR, took six months and cost around AUD 80,000. Although the capacity of the existing pavement was determined and future upgrade options were better understood, the practical return on the investment was negligible.

\subsection{Example 3 - Proserpine airport}

Proserpine airport was upgrade by partial reconstruction and structural asphalt overlay in 2017. Prior to the upgrade the PCN (Equation 7) was lower than the ACN of the using A330300 aircraft, which is 58 on flexible pavement with a category A subgrade. Following the upgrade, the PCN was increased to reflect the A330-300, as shown in Equation 8, although the B737-800 remained the dominant aircraft based on frequency, but was not the critical aircraft for pavement thickness determination. Interestingly, during the upgrade design, the subgrade was found to have a characteristic CBR value of 18 , resulting in the change from PCN subgrade category B to category A.

$$
\begin{aligned}
& \text { Proserpine pre - upgrade PCN 46/F/B/X/T } \\
& \text { Proserpine post-upgrade PCN 58/F/A/X/T }
\end{aligned}
$$

Because the pavement was recently upgraded, which included significant geotechnical investigations, the existing pavement structures were well known. The pavement upgrade design and construction records were also available, meaning that the basis of the current strength rating (Equation 8) was clearly documented. Consequently, the conversion from, PCN to PCR only required the calculation of the A330-300 ACR. Although the prescriptive process could be followed, the intent of the strength rating remained to allow the A330-300 to operate in an unrestricted manner, and the change from ACN-PCN to ACR-PCR did not change this. The resulting PCR for Proserpine airport is shown in Equation 9.

$$
\text { Proserpine PCR } 754 / F / A / X / T
$$

Despite this being the simplest of all the examples presented in this paper, the airport was unable to determine the PCR without assistance from a specialist engineer. This required the specialist engineer to review the documentation associated with the 2017 pavement upgrade and calculate the PCR of the A330-300 and recommended the published PCR in a short report. In total, one day of a specialist engineer was required, costing around AUD 2,000. 


\subsection{Example 4 - Brisbane airport}

Brisbane airport is a major international airport with two main runways of comparable strength. The original runway was constructed in the 1980s and the new runway was completed in 2020. The airport is also unusual in that it is constructed on a deep sand fill, typically 2.0-2.5 m thick, over low CBR marine clay subgrade. Although the strength ratings reflect the clay as the subgrade (category D), the pavement structures were designed to protect the sand fill, which has a typical CBR value greater than 20 (category A). Prior to the new runway's construction, the old runway accommodated all current domestic and long haul aircraft, up to and including the B777-300ER, despite having a strength rating (Equation 10) lower than the $\mathrm{ACN}$ of the B777-300ER, which is 120 for a flexible pavement on a category D subgrade. The new runway has a higher PCN (Equation 11) and the basis of the new runway strength rating is not known, although the new runway was designed to carry the same aircraft as currently uses the old runway.

$$
\begin{aligned}
& \text { Brisbane old PCN } 108 / F / D / X / T \\
& \text { Brisbane new PCN } 124 / F / D / X / T
\end{aligned}
$$

It is expected that the two Brisbane airport runway PCN values resulted from a technical evaluation using the current FAA method of PCN determination using COMFAA. Despite the old runway PCN being rated significantly lower than required for the B777-300-ER, the old runway has supported B747-400, A380-800, A350-900 and B777-330ER operations multiple times per day in recent years. When the two runway structures were evaluated under the new FAA PCR determination method (FAA 2020) the results were similarly different, as shown in Equation 12 and Equation 13.

$$
\begin{aligned}
& \text { Brisbane old PCR } 1112 / F / D / X / T \\
& \text { Brisbane new PCR } 1272 / F / D / X / T
\end{aligned}
$$

The rating of the new runway to a level that exceeds all practically expected aircraft is questioned. Regardless of whether the strength rating is PCN 124 (compared to an ACN of 120) or PCR 1272 (compared to an ACR of 1233), over-rating the pavement simply because that is the outcome of the prescriptive FAA strength rating process is unjustified. Furthermore, maintaining a lower rating for the old runway, whether PCN 108 or PCR 1112, is also not recommended, because the runway has been supporting aircraft up to the B777-300ER (ACN 120 or ACR 1233) multiple times a day for some years. Consequently, it is recommended that both runways be re-rated to reflect the ongoing regular use of the B777-300ER, as shown in Equation 14.

$$
\text { Brisbane recommended PCR } 1233 / F / D / X / T
$$

\section{TRANSITIONAL IMPLICATIONS}

The ACN-PCN system has been in place for almost 30 years, since 1981, and during that time has only been subject to minor variations, as described above. Consequently, ACN-PCN is well entrenched in the strength rating and aeronautical information publications (AIP) of ICAO member States around the world. Consequently, the change to ACR-PCR will be significant for airports across the globe and this will undoubtably create some transitional challenges.

ICAO are permitting member States to transition from ACN-PCN to ACR-PCR anytime from July 2020 until November 2024. This will require aircraft manufacturers to publish both 
ACN and ACR values for their aircraft until at least the end of 2024. It will also require the FAA and other organisations that produce ACN calculators, such as COMFAA (FAA 2014a) and PCN strength rating guidance (FAA 2014b) to update their guidance and eventually withdraw the ACN-PCN based documentation. On a national scale, each ICAO member State will either need to transition all airports on a single day, or allow a similar period of optional strength rating. Because it is impractical for AIP producers to run parallel systems and for an aircraft to take-off from Brisbane on a PCN and land in Sydney on a PCR, it is expected that all Australian airports will transition on a single day, which will create additional challenges.

\subsection{Re-publication}

There are approximately 700 registered airports in Australia. Of these, around 480 have a strength rating, of which around 350 have a PCN (White et al. 2021). The others are generally for general aviation and have a $5,700 \mathrm{~kg}$ aircraft mass limit. Each airport publishes its PCN online and in print, in a document known as the ERSA (ASA 2020). The ERSA is updated every three months and hard copies are distributed to more than 1,000 registered users. If all 350 airports with a current PCN are required to transition to a PCR on the same date, then 350 (of the 480) ERSA entries will need to be updated in the same revision of the ERSA. Such a significant revision is expected to put substantial strain on the publishers of the ERSA.

\subsection{Subgrade categorization}

Many of the changes associated with the ACR-PCR system will not affect the users greatly. For example, an airport does not need to understand the differences between the simple Boussinesq model used by COMFAA and the more complex layered elastic model used by FAARFIELD. However, airports do need to understand their subgrade bearing strength in order to appropriately publish their strength rating based on the correct subgrade category. Many airports know their subgrade category, from the current PCN, but not the actual characteristic subgrade CBR value.

The subgrade category of any given airport may change in the transition from ACN-PCN to ACR-PCR. Not all airports will have a subgrade bearing strength that will change their subgrade category when transitioning to ACR-PCR. In fact, only airports with a characteristic subgrade bearing capacity of:

- CBR 5. Will move from category $\mathrm{C}$ to category D.

- CBR 9. Will move from category B to category C.

- CBR 13-14. Will move from category A to category B.

However, if all an airport knows is that they are currently in subgrade category $\mathrm{C}$ (CBR 5-8), they will no longer know if they remain a category $\mathrm{C}$ (CBR 6-9) or move to a subgrade category $\mathrm{D}$ (CBR 5 or less). To determine whether they need to change subgrade categories, they first need to know their characteristic CBR value and this is an expensive process for many regional airports. The irony is that the new subgrade CBR values are of no tangible benefit and do not contribute to the desire to reduce the mismatch between strength rating and the basis of pavement design. Instead, ICAO could have removed the subgrade categories all together and used actual subgrade CBR values. The original categories were only provided to simplify the system, which was originally based on ACN charts and tables, meaning that many different subgrade categories would create an unwieldy system. However, in modern times, all ACN/ACR calculations are performed using tablet applications and computer software, meaning that any number of subgrade categories could be included in the system without causing any issue. It would have improved the accuracy of the system by simply using each CBR value from 3 to 15 , 
with a high and low bucket at each end, represented by CBR 2 (for values 2 or less) and CBR 20 (for values 16 and greater).

\subsection{Existing pavement strength ratings}

The transition to ACR-PCR will highlight that the basis of many regional airport current PCN values is not known. Many Australian airports were assigned a usage based PCN at the time the airport was transferred from the Commonwealth to local government agencies. In some cases, the historical strength rating is not reflected by the current airport operations and in many cases an expensive geotechnical investigation and engineering assessment will be required. Furthermore, these assessments may result in strength ratings being downgraded, despite historically good performance under significant aircraft loading. Therefore, these airports will feel obliged to use the services of a specialist engineer to make a usage based assessment or judgment and that will add to the expense. In many cases, the ACN-PCN system has served these airports well and they are generally not challenged by the mis-match between the strength rating system and pavement thickness design. However, they will still incur the cost of transitioning from ACN-PCN to ACR-PCR.

\subsection{Cost to industry}

The cost of transitioning to the ACR-PCR system is significant. The cost was estimated for Australia's 350 airports with a current PCN, based on a range of approximations:

- $15 \%$ of airports undertake geotechnical investigations and use a specialist engineer to determine a PCR value based on a balance of the prescriptive FAA process, reverse engineering of their existing pavement structures and observed pavement performance under longer term using aircraft.

- $20 \%$ of airports use a specialist engineer to determine a PCR value based on historical records and reverse engineering of their existing pavement structure.

- $60 \%$ of airports use a specialist engineering to determine a PCR value that is equivalent to their current PCN value, on the grounds that the basis of the current pavement strength rating is well known.

- $5 \%$ of airports convert their current PCN to an equivalent PCR based on their using aircraft or the known basis of the current pavement strength rating and they perform this task internally.

Based on the examples presented in this study and the time required to perform the various analyses, the cost to each airport is expected to be:

- Geotechnical investigation and reverse engineering by a specialist engineer. AUD $50 \mathrm{k}$.

- Reverse engineering by a specialist engineer based on historical records. AUD $10 \mathrm{k}$.

- Calculation of an equivalent PCR and review of using aircraft by a specialist engineer. AUD $2 \mathrm{k}$.

- Calculation of an equivalent PCR value internally. No cost.

When the cost per airport is applied to the portion of the 350 airports that will undertake this assessment, the total cost to the industry is estimated to be AUD 3.75 million. This may be justified if there was a tangible benefit to the airports, in the form of allowing bigger aircraft to operate or the better protect pavements from overloads or to enable better quantification of the implications associated with allowing Pavement Concessions. However, none of those factors will be improved because the actual strength of the pavements will not increase and the current system is rating the pavement strength appropriately. In Australia, and other countries where the prescriptive processes detailed in the FAA guidance for determining airport pavement strength ratings are not mandated or commonly applied, the cost to industry will be incurred without any tangible benefit whatsoever. 


\section{CONCLUSION}

A robust and reliable airport pavement strength rating system is essential for the management of airport pavements around the world. The current system has served airports well since 1981 but will be replaced by a new, more rational system, for all ICAO member States by 2024 . Case studies on four Australian airports indicate how the new system will be implemented in countries that do not mandate prescriptive methods of PCN determination, rather deferring to engineering judgment exercised by specialist engineers based on historical using aircraft, historical pavement performance and reverse engineering of existing pavement structures. The transition to the new system will create some challenges, mostly for those airports that do not know the basis of their current strength rating and can not locate historical existing pavement composition and subgrade bearing strength data. The cost of transition is estimated to be significant and is not justified because the new system provides no practical benefit to the majority of Australian airports.

\section{REFERENCES}

AAA, 2017, Airfield Pavement Essential, Airport Practice Note 12, Australian Airports Association, Canberra, Australian Capital Territory, Australia, April, accessed 17 September 2020, https://airports.asn. au/airport-practice-notes/.

Ahlvin, R. G. 1991, Origin of Developments for Structural Design of Pavement, Technical Report GL9126, US Army Corps of Engineers, Waterways Experiment Station, Vicksburg, Mississippi, USA.

ASA 2020, Aeronautical Information Package, En-Route Supplement Australia, Airservices Australia, 5 November 2020, accessed 18 September 2020, https://www.airservicesaustralia.com/aip/aip.asp? $\mathrm{pg}=40 \&$ vdate $=05 \mathrm{NOV} 2020 \& \mathrm{ver}=2$.

CASA 2011, Strength Rating of Aerodrome Pavements, Advisory Circular AC139-25(0), August, accessed 31 July 2015, https://www.casa.gov.au/sites/g/files/net351/f/_assets/main/rules/1998casr/ 139/139c25.pdf.

CROW 2003, The PCN runway strength rating and load control system, CROW report 04-09, CROW.

Deilami, S. \& White, G. 2020, 'Review of reflective cracking in composite pavements;, International Journal of Pavement Research and Technology, no. 13, pp. 524-535.

FAA 2014a, COMFAA 3.0, Federal Aviation Administration, 14 August, accessed 18 September 2020, https://www.airporttech.tc.faa.gov/Products/Airport-Pavement-Software-Programs/Airport-SoftwareDetail/ArtMID/3708/ArticleID/10/COMFAA-30

FAA 2014b, Standardized method of reporting Aircraft Pavement Strength - PCN, Advisory Circular 150/ 5335-5C, Federal Aviation Administration, Washington, District of Columbia, USA, 14 August.

FAA 2017, FAARFIELD, Version 1.42, Federal Aviation Administration, Washington, District of Columbia, USA, 18 September, accessed 17 December 2017, http://www.airporttech.tc.faa.gov/Down load/Airport-Pavement-Software-Programs/Airport-Software-Detail/ArtMID/3708/ArticleID/4/ FAARFIELD-142.

FAA 2020, Airport Improvement Program, Federal Aviation Administration, accessed 18 September 2020, https://www.faa.gov/airports/aip/.

Fabre, C. 2018, 'The Aircraft Classification Rating - Pavement Classification Rating ACR-PCR', ALACPA 2018, Quito, Ecuador, 28 May to 1 June.

Fabre, C. 2019, 'The ACR-PCR Method', International Coordinating Council of Aerospace Industries Association, 15 September.

Fabre, C., Balay, J., Lerat, P. \& Mazars, A. 2009, 'Full-scale aircraft tire pressure test', Eighth International Conference on the Bearing Capacity of Roads, Railways and Airfields, Urbana-Champaign, Illinois, USA, 29 June - 2 July, pp. 1405-1413.

Fabre, C. \& Vaurs, G. 2017, 'Development of rational ACN/PCN system', 10th International Conference on the Bearing Capacity of Roads, Railways and Airfields, Athens, Greece, 28-30 June.

ICAO 2013, Aerodrome Design and Operations. Annex 14, Volume 1, to the Conventions on International Civil Aviation, International Civil Aviation Organization, Montreal, Canada, February.

ICAO 2020, Member States, International Civil Aviation Organisation, 1 October 2019, accessed 18 September 2020, https://www.icao.int/about-icao/Pages/member-states.aspx.

Roginski, M. J. 2007, 'Effects of aircraft tire pressures on flexible pavements', Advanced Characterisation of Pavement and Soil Engineering Materials, Athens, Greece, 20-22 June, Taylor and Francis, pp. 1473-1481. 
Roginski, M. J. 2013, 'ICAO update - status of high tyre pressure revision to Annex 14', FAA Working Group Meeting, Atlantic City, New Jersey, USA 15-17 April, Federal Aviation Administration.

Wardle, L. J. \& Rodway, B. 2010, 'Advanced design of flexible aircraft pavements', 24th ARRB Conference, Melbourne, Victoria, Australia, 12-15 October, ARRB Transport Research.

White, G. 2019, 'A standardised sprayed sealing specification for Australian airports', 12th Conference on Asphalt Pavements for Southern Africa, Sun City, South Africa, 13-16 October, pp. 806-821.

White, G., Kelly, G., Fairweather, H. \& Jamshidi, A. 2020, 'Theoretical socio-enviro-financial cost analysis of equivalent flexible aircraft pavement structures', 99th Annual Meeting of the Transportation Research Board, Washington, District of Columbia, USA, 12-16 January.

White, G., Farelly, J. \& Jamieson, S. 2021, 'Estimating the Value and Cost of Australian Aircraft Pavements Assets', International Airfield and Highway Pavements Conference, 8-10 June, a virtual event.

Disclaimer:

The views expressed in this paper are solely those of the author and are not necessarily supported or endorsed by the airports that own, operate and manage the runways that have been used as the case study examples. In some cases, existing pavement and aircraft data has been amended to improve the educational value of the examples presented in the case studies. Airports should not rely on the calculations and values presented in this paper to determine the PCN or PCR of their runway. 